\title{
Examining Power Relationships in the Use of Information Systems to Comply with Laws and Enable Social Inclusion
}

\author{
Shiya Cao \\ Worcester Polytechnic Institute \\ scao2@wpi.edu
}

\author{
Diane Strong \\ Worcester Polytechnic Institute \\ dstrong@wpi.edu
}

\author{
Eleanor Loiacono \\ The College of William and Mary \\ eleanor.loiacono@mason.wm.edu
}

\begin{abstract}
This study employs the circuits of power framework to analyze how power relationships affect the use of Information Systems (IS) in the social inclusion context. This research majorly contributes to social inclusion research in IS by examining how the power relationships influence the use of IS and how IS design can address complex power relationships and enable social inclusion.
\end{abstract}

\section{Introduction}

Social inclusion, according to the United Nations, is defined as the process of improving participation in economic and social life, particularly for people who are disadvantaged, through enhancing opportunities, access to resources, voice and respect for rights [29]. For many, information systems (IS) are integral to engaging in nearly every social aspect and to maintaining social roles and relationships [3]. Thereby IS are considered as an important tool to enable and enhance social inclusion [22][28]. Particularly, IS at work help support involvement, productivity, and social interaction of disadvantaged individuals, thereby improving social inclusion [11]. Thus, social inclusion research in IS is critical to understand human diversity in relation to IS use and organizational practices [28].

The social inclusion context embraces complex power relationships and different organizational actors play roles in it. Legislators make laws and regulations to protect disadvantaged individuals. Covered organizations are mandated to obey these laws and regulations so that they equally include disadvantaged individuals in the workplace. This paper specifically focuses on integrating disabled people into the workplace. According to Title I of the Americans with Disabilities Act of 1990 (ADA) and the Equal Employment Opportunity Commission (EEOC), organizations with 15 or more employees are required to provide reasonable accommodations [27]. Through an effective accommodation process, disabled employees can get the support they need, integrate into their work environments, and enjoy the same benefits of employment as others [6][18]. On the other hand, organizations need to maintain efficient operation and financial benefits. There could be controversy between accommodation compliance and business needs. Many studies have shown that business costs of providing accommodations are a big concern for organizations [2][5][7][12][14][16].

We are interested in the role of power relationships in the use of IS that help facilitate the accommodation process and integrate disabled people into the workplace. We examine this phenomenon through a case study in a multinational information technology (IT) organization headquartered in the United States. This organization used an in-house work accommodation (WA) system, which managed its process for handling work-related accommodations. This paper highlights that this organization makes a compromise between accommodation compliance and business needs as well as makes changes to form legitimacy of IS used in the accommodation process. This study proposes IS design principles using emancipatory pedagogy to address complex power relationships and emancipate disabled employees.

This paper: (1) contributes to social inclusion research in IS by examining complex power relationships in the social inclusion context and developing IS design principles to address the power relationships using emancipatory pedagogy; (2) extends the use of the circuits of power framework to the social inclusion context; (3) integrates perspectives from IS, social inclusion, power relations, legal, and organizational change studies to provide a novel understanding of the legitimacy of IS to comply with laws and enable social inclusion.

This paper proceeds as follows. Section 2 reviews disability and accommodation legislation as well as the circuits of power framework. Section 3 discusses a methodology of an interpretive case study. Section 4 presents the findings of the case study interpreted by the circuits of power framework. Section 5 proposes IS design principles using emancipatory pedagogy and 
delineates the limitations of this paper and further research.

\section{Literature review}

\subsection{Disability and accommodation legislation}

This section discusses the background of building an organizational accommodation process facilitated by IS. As mandated by law and regulations, covered organizations must provide reasonable accommodations to disabled employees and conduct interactive dialogues to explore accommodation options. The ADA of 1990 is a primary law that prohibits discrimination based on disability and requires covered employers to provide reasonable accommodations [27]. It is enforced by the EEOC, which investigates, mediates, and settles discrimination complaints, as well as files discrimination suits against employers on behalf of alleged victims [32]. The influence of the ADA on covered employers has been increased since the ADA Amendments Act of 2008 (ADAAA) broadened the definition of the term "disability", including diabetes, multiple sclerosis, major depression, bipolar disorder, etc. that were not covered in the original text of the ADA [30][31]. As a result of the ADAAA and EEOC's regulations, it has become easier for individuals seeking the law's protection to demonstrate that they meet the definition of "disability" [30]. Accordingly, more ADA claims related to reasonable accommodations have occurred [13]. In addition, the EEOC publishes a list of pending and resolved cases under the ADA on its website (https://www.eeoc.gov/selected-case-lists) and such cases have received more and more attentions from the media as of late, which can have a big impact on an organization's reputation. These law and regulations influence covered organizations to provide disabled employees with an effective accommodation process.

The core of an accommodation process is an interactive dialogue about an employee's accommodation options between the employee and his/her employer [31]. The EEOC suggests that an employer should engage in an interactive dialogue with an employee because the disabled individual has the most knowledge about his/her accommodation needs [31]. An effective interactive dialogue should enable the employer to acquire the necessary information to determine the feasibility of granting a reasonable accommodation without causing an undue hardship [31]. Interactive dialogue, presenting evidence of whether or not participating in the accommodation processes was in good faith, is considered as the foundation of compliance with the ADA and the EEOC's regulations [31]. Specifically, the case study organization in this research had $90 \%$ of its job accommodation requests as medical leave requests. Medical leave is a reasonable accommodation in a qualifying situation under the ADA [9][31]. When employees exhaust 12 weeks of leave under the Family and Medical Leave Act (FMLA) and still cannot return to work due to their medical condition, an interactive dialogue is necessary to determine if extended medical leave is an ADA qualifying situation [9]. If an extended leave poses an undue hardship on the business, the employer needs to demonstrate why [9].

Through extensive communications and exchanges with disability and accommodation experts, we have found that accommodation management systems can be an effective tool to facilitate an interactive accommodation process. However, there is little research on how IS have been used in accommodation processes. In this research, we explore the effect of power relationships on the use of an accommodation management system, by employing the circuits of power framework, which is elaborated in the following section.

\subsection{Circuits of power framework}

We chose the circuits of power framework because it is a legitimate theoretical framework for IS researchers to examine power relationships, which fits well with the social inclusion context that embraces complex power relationships [24]. It integrates different insights including power relationships, techniques, organizational actors, and environmental factors [8].

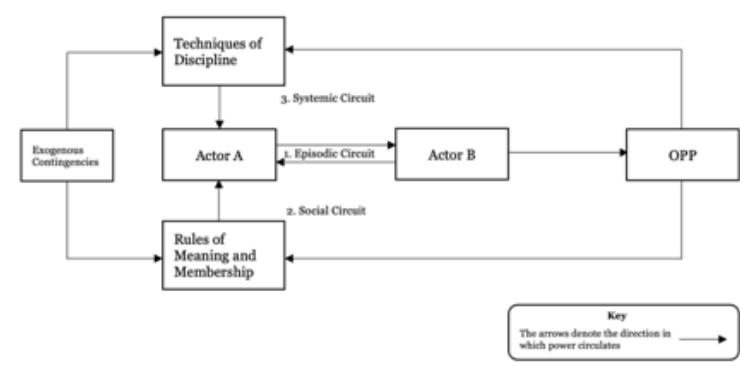

Figure 1. Circuits of power framework (adapted from Frameworks of Power, S. R. Clegg, 1989)

The circuits of power framework, created by Stewart Clegg (1989), has been applied to IS studies in government and various organizations [1][23]. It uses the metaphor of an electrical circuit to interpret power relations [24]. In this framework, there are three circuits of power: episodic, social, and systemic [1].

The circuit of episodic power emphasizes causal power that is exercised [23] (see 1. Episodic Circuit is a loop between Actor A and Actor B in Figure 1). It represents that Actor A exercises power over Actor B when A makes B do something that B would otherwise not do [23]. Power, however, is not a unidirectional 
relationship: B usually has options in terms of how they comply and the extent to which they comply [23].

Influenced by the power relationship between $\mathrm{A}$ and B, an Obligatory Passage Point (OPP) is created (see Figure 1). OPP refers to what A wants B to do [1][4], e.g., an OPP is created when legislators (A) require organizations (B) to follow accessibility guidelines for their websites; otherwise, they will face potential lawsuits. In the present study, legislators (A) created an OPP when they asked for an interactive accommodation process. The case study organization (B) complied by creating an accommodation management system to facilitate an interactive accommodation process, i.e., the IS can be viewed as an OPP [23].

While legislators (A) did not directly ask the case study organization (B) to adopt an accommodation management system, we argue that from a sociotechnical perspective, IS involve technology, process, tasks, and people [20], therefore, an interactive accommodation process that legislator (A) requested is part of the system. An IS is critical to harmonize an organizational process [20]. Thus, an accommodation management system can be viewed as an OPP, without which an organization would face legal risks.

The circuit of social integration focuses on rules of meaning and membership that exert an impact on organizational actors [1] (see 2. Social Circuit in Fig. 1, which is a loop through Actor A, Actor B, OPP, and Rules of Meaning and Membership). It relates to the condition that provides $\mathrm{A}$ with the resources and legitimation to exercise power over B [1]. For example, disability and accommodation legislation was made because of emerging societal trends of improving disability inclusion. Such increasing awareness and related alliances promoted relevant legislation. Thus, legislators (A) were able to influence the actions of organizations (B).

In the present study, as we talked with disability and accommodation experts, there was still a lack of a standard of IS used to manage the accommodation process across organizations-a few organizations used more advanced accommodation management systems than others. The allies or discourse to recognize the meaning of using accommodation management systems have not been formed, thereby providing few resources to legislators. Thus, the circuit of social integration is lacking in current IS practices in the accommodation process. Hence, we do not analyze this circuit in this paper.

The circuit of systemic integration centers on power exercised through techniques of discipline, which facilitates B's compliance through normative desires and often relates to the OPP to which B is directed [25] (see 3. Systemic Circuit in Fig 1, which is a loop through
Actor A, Actor B, OPP, and Techniques of Discipline). System integration is usually achieved when there is a fit between techniques of discipline the OPP utilizes and organizational practices [1]. For instance, organizations integrate and fit the checklists of accessibility guidelines well into their website design practices. Thus, the OPP (accessibility guidelines in the example) becomes further legitimate through the circuits of systemic integration [1].

Changes in circuits of power are introduced by exogenous contingencies, such as stricter regulations. These incidents influence rules of meaning and membership as well as techniques of discipline [1] (see Figure 1).

\section{Methodology}

We take an interpretive approach using the circuits of power framework as a lens to analyze the role of power relationships in the use of an accommodation management system [21]. Specifically, we apply the circuits of power to frame the narrative of the case and interpret the case data to gain the meaning of IS and power relations [1][21].

\subsection{Case study organization and data collection}

As we talked with disability and accommodation experts as well as interviewed other organizations that have used accommodation management systems, we found that systems currently used in the accommodation process have similar structures, roles, tasks, and processes. In this paper, we chose our case study organization because we were able to interview multiple stakeholders including different accommodation teams in this organization, which enabled us to analyze how an accommodation management system was used in the accommodation process.

The case study organization is a multinational IT organization headquartered in the United States with over 200,000 employees. It operates numerous retail stores often with a recent graduate as a manager (supervisor) in each store. This organization developed an in-house WA system to replace an outsourcing accommodation service in 2020. As the first phase of the transition project, the WA system currently covered medical leave requests for disabled employees. The organization will bring work accommodation requests (e.g., ergonomic keyboards and chairs) in-house in the second phase of this project.

The unit of analysis of our case study is the WA system, which includes the system, its users, and three accommodation teams that belong to human resources 
(HR) to support the organization's accommodation process. Supervisors use the WA system to make accommodation decisions and record interactive dialogues.

We collected data through interviews with HR and IT staff as well as a supervisor between September 2020 and April 2021. To gain access to the case study organization, a recruitment email was sent to a contact on an accessibility association email list. After an initial research introduction meeting with the contact, we were introduced to an HR manager in this organization and then were able to schedule eight semi-structured interviews with the HR manager, three HR specialists in different accommodation teams, an IT manager who oversaw the in-house project, and the initial contact from a supervisor's perspective (see Table 1). An interview protocol with open-ended questions was used to gain insights into the WA system and participants' experiences in the accommodation process. The average interview length was 60 minutes. Besides the interviews, archival files such as medical evaluation form and interactive dialogue form were also collected from participants.

Table 1. Distribution of interviews across different roles

\begin{tabular}{|l|c|}
\hline \multicolumn{1}{|c|}{ Role } & \# of Interviews \\
\hline HR Manager & 2 \\
\hline Medical Support Specialist & 1 \\
\hline Accommodation Support Specialist & 1 \\
\hline Interactive Dialogue Specialist & 1 \\
\hline IT Manager & 1 \\
\hline Supervisor & 2 \\
\hline
\end{tabular}

\subsection{Data analysis}

Data analysis followed the circuits of power framework to illuminate the case by conducting a dialogical process between data and theory [1][15]. The first step was to understand the creation, structures, and tasks of the WA system used in the case study organization's accommodation process. This was achieved by reading and coding the interview transcripts and archival files. The NVivo 12 software package was used to support coding and analysis. The initial coding was an open coding process, identifying descriptive categories through a sentence-by-sentence analysis and resulting in 73 open codes covering the broad set of concepts such as accommodation process, structure, and IS use. Once the initial coding was completed, the first author drafted a narrative of the case including the creation of the WA system, the organization's accommodation procedures facilitated by this system, and how three accommodation teams supported the procedures.
The second step was to interpret the data and identify theoretical themes. After the first author discussed the preliminary findings with her dissertation committee members (other authors), the circuits of power framework was viewed as a lens to interpret the power relationships in the use of the WA system that emerged from the collected data. The outcome of this step was interpreting the data for each circuit of power and for the exogenous contingencies.

The last step of the analysis was to further develop and integrate theoretical themes in the circuits of power framework. The circuit of episodic power focuses on the creation and development of the WA system, which reveals that the organization needs to make a compromise between accommodation compliance and business needs to legitimize the WA system. The circuit of systemic power is associated with the fit between the accommodation practices facilitated by the WA system and the organization's business practices, which demonstrates that organizational changes are needed to legitimize the WA system.

Moreover, we validated our analysis according to the evaluation criteria for interpretive case studies with a realist view (an accurate representation of reality) suggested by Sarker et al. [21]. Our reflections on their five evaluation criteria are as follows.

The first criterion is thick description and insights. We illustrated the creation, structures, and tasks of a sociotechnical system used in an organization's accommodation process. We also revealed the effect of the power relationships on the use of this system as well as necessary organizational changes to make this system work for its intended purposes.

The second criterion is quality of the theoretical scaffolding. The power relationships emerged from the collected data, which supported us to apply the circuits of power framework. Moreover, we developed theoretical themes alongside the narrative of the case focusing on an accurate representation of reality.

The third criterion is interaction between researcher and subject. The interviews were semi-structured and an interview protocol with open-ended questions was used so that participants could provide their interpretations of the WA system and discussed their experiences in the accommodation process.

The fourth criterion is contextualization. Prior to the present study, we had extensive communications and exchanges with disability and accommodation experts regarding accommodation process and technology topics. During the interviews, participants were asked to recollect the context surrounding the events that led to the creation and development of the WA system.

The fifth criterion is self-reflexivity. Data analysis was conducted with reflexivity. The representativeness 
of data was checked and the spurious relations were ruled out. Additionally, archival files were collected with the purpose of fact-checking.

\section{Findings}

\subsection{Exogenous contingencies}

The prime motive for the transition project from an outsourcing to in-house accommodation system is to improve compliance with disability and accommodation law and regulations. Large organizations like the case study organization are increasingly forced to comply with law and regulations because they have larger financial resources than mom and pop businesses and thus have fewer reasons to argue that accommodations cause an undue hardship on the business, as the HR manager indicated:

"The burden of proof on [the case study organization] to say that we have a hardship for an accommodation is very high because we're a [large organization]. There's not a lot of accommodations we can't accommodate."

Participants confirmed the importance of accommodating and conducting interactive dialogues that the WA system would help them do so. If the organization failed to do so, the reputation and monetary costs of accommodation litigation were huge.

"There's a lot of litigation around job accommodations for failure to accommodate, failure to engage in the interactive process. I think from a reputational perspective, [the WA system] is going to help us because if we settle with the EEOC, many times that is public... [job accommodation settlement] is published on the EEOC website and it also receives a lot of media attention." (HR manager)

"Some of the other companies where they didn't accommodate and [a lawsuit] was like billions of dollars for the [companies]." (Accommodation support specialist)

\subsection{Circuit of episodic power}

The circuit of episodic power focuses on the case study organization's creation and development of an accommodation management system to comply with law and regulations as well as meet its business needs.

Episodic power is circulating between the EEOC (A), a federal agency that administers and enforces civil rights laws against workplace discrimination, and covered organizations like the case study organization (B) that are required to provide reasonable accommodations to disabled employees.
On the one hand, episodic power plays an important role in the creation of the WA system. On the other hand, this organization figures out how to make the system work in order to balance accommodation compliance and business needs. These points are elaborated in the following subsections.

4.2.1. The role of episodic power in the creation of the WA system. As the preceding analysis showed, the case study organization as a large organization feels pressure to comply with the ADA and EEOC regulations because litigation risks are high to them. To better comply with rules and regulations, this organization created an in-house accommodation management system to replace an outsourcing service. There are 2 major reasons behind this transition: (1) emphasizing interactive dialogues; (2) increasing efficiency of accommodating.

First, due to the key role of interactive dialogues in compliance with the ADA and the EEOC's regulations, the in-house WA system mandates stakeholders to document these dialogues. The outsourcing service lacked this requirement. Recording interactive dialogues was optional in the outsourcing vendor's system. Supervisors, who were usually the decision maker in accommodation exploration, did not always understand the importance of holding these dialogues. As a result, there was a lack of interactive dialogues taking place. The case study organization also had to rely on the vendor to come to them if supervisors were not cooperating or escalated denial of accommodation requests, which increased legal risks for the organization. In contrast, the WA system required supervisors to fill out an interactive dialogue web form before they could make an accommodation decision, along with the support of different accommodation teams, which helped increase the effectiveness of interactive dialogues and accommodating.

Second, with the high volume of requests, the case study organization needs to increase efficiency of its accommodation process and provide a better service to employees. The vendor's service was not efficient enough to meet the organization's need. For example, medical evaluation of an accommodation request, as the first step of accommodation management, took three weeks to three months by the vendor (from receiving a request to sending an initial medical evaluation to an employee; not including time needed to resubmit the request by the employee if the original request is incomplete). One of the reasons of slow turnaround times was that the vendor was not allowed to have access to the organization's internal systems and had to ask HR staff in the organization for relevant information to determine eligibility of an accommodation request. Another reason was that the vendor did not have a "fastmoving" culture as the case study organization had. In 
contrast, the in-house WA system can handle accommodation requests in a timely manner. The WA system is automated by connecting relevant internal systems. For instance, it can automatically retrieve an employee's job descriptions using her/his employee ID $\mathrm{s} /$ he entered when requesting an accommodation, which saves the manual checking time. In the medical evaluation example, with an apples-to-apples comparison, the WA system only took on the average of three days to complete the medical evaluation step. These improvements help this organization as player (B) in the power relationship to better comply with rules and regulations enforced by the EEOC (A).

4.2.2. The compromise between accommodation compliance and business needs by creating a new accommodation team. Episodic power is not one-way traffic: the organization as player (B) usually has options in terms of how they comply and the extent to which they comply [25]. In the present case, this organization met its business needs by developing a new team that supports supervisors on how to conduct an interactive dialogue so that the organization can achieve its business needs and compliance. The HR manager mentioned that they "have a lot of absenteeism associated with job accommodation", and " $83 \%$ of all of their medically supported job accommodations were supported as written". The case study organization is required to accommodate disabled employees, however, as a business, it needs to operate efficiently, get their employees back to work, and maintain financial benefits. To resolve any conflicts between accommodation compliance and business needs, this organization created a new team, which was not available in the vendor's service, to counsel supervisors on how to have interactive dialogues with employees and accommodate them based on their individual situations.

The HR manager demonstrated the need of this team as follows.

"As I was working with [supervisors], I was seeing this trepidation with the [supervisors] when they would receive the medically supported accommodation that they just felt they had to approve it as is. And either that or if they understood they could do the interactive dialogue, they really didn't understand the flexibility that they have with the interactive dialogue... I recognize that to protect [the case study organization] to make sure that we're doing the mandatory legally required interactive process...this team works with [supervisors] to offer them questions that they can ask that can help understand what the employee's need is and how we can accommodate that and meet the needs of the business."

\subsection{Obligatory passage points}

4.3.1. Problematization. When episodic power is exerted, problematization is a necessary step for a receiver to accept an OPP as the outcome of episodic power [23]. An effective problematization convinces stakeholders to accept that the only way to solve their problem is to use the OPP as their channel [23]. We mentioned some aspects of the problematization when discussing the creation of the WA system. This section further examines the details of the WA system as an OPP.

The WA system has three teams to support the accommodation process: a medical support (MES) team, an accommodation support (ACS) team, and an interactive dialogue support (IDS) team. The outsourcing service had teams equivalent to the MES and ACS team. The in-house WA system increases efficiency of accommodating by automatically connecting relevant internal systems as the medical evaluation example indicated in Section 4.2.1. Moreover, the WA system is beneficial for documented interactive dialogues so that the organization can improve compliance with law and regulations, as illustrated in the HR manager's comparison of the interactive dialogues situation pertaining to pre-system versus post-system:

"Before the [WA system], we had an expectation that [the interactive dialogue] was documented and saved, but we didn't ever check it. We really didn't have any way of knowing whether [supervisors] had conducted the interactive dialogue or not because they just responded back saying we have accommodated as written or we've denied it or it's been the modified accommodation. We wouldn't have any view into the interactive dialogue. With the new [WA system], we require [supervisors] before they can respond in any way to approve, modify, or deny, they must fill out and tell us about their interactive dialogue. It's automatically stored. What we were finding is true litigation on job accommodations--there were a lot of missing forms for interactive dialogue. Now for every single job accommodation, we have a documented interactive dialogue. The quality is skyrocketing, just going through the roof because we're forcing the supervisors to hold the interactive dialogue."

Furthermore, the WA system helps regulate the accommodation procedure. For example, the WA system is useful for creating a behavior of accommodating by escalating a request to the ACS team when the request is modified or denied by a supervisor. The HR manager referred to this function as "a failsafe":

"We have a fail-safe in place so that supervisors can't just deny an accommodation because we know 
how important it is to make sure that we accommodate whenever possible."

An ACS specialist confirmed this: "[Supervisors] are not allowed to deny [a request] until they have discussed it with [an ACS specialist]."

4.3.2. Enrolment, which implies that stakeholders legitimize an OPP through bargaining and making adjustments [23]. As a result, the legitimacy of the OPP is recognized [23].

A few months after the WA system was launched, a new IDS team was introduced to the accommodation process in a pilot section in the case study organization. The vendor's service did not have the interactive dialogue support as the IDS team offers.

The IDS team, as an intermediator between a supervisor and employee, helps make a compromise between accommodation compliance and business needs. This team uses two strategies to help reduce absence hours and protect the business: (1) reviewing an employee's attendance record to decide accommodations, (2) offering a flexible schedule instead of granting a medical leave. First, the IDS team helps decide accommodations based on an employee's attendance history. Once a leave request is medically supported, the IDS team conducts an analysis of the attendance history of the employee who requests the leave. According to the EEOC, determining whether granting a leave would cause an undue hardship may consider the length and frequency of the leave [31]. Besides, if an employee's medical condition prevents him/her from performing one or more essential job functions even with a reasonable accommodation, this situation would pose an undue hardship [31]. The case study organization considers an employee who has been off work on disability for a long period of time (e.g., an employee who has only worked $10 \%$ or $15 \%$ of his/her scheduled hours over the last five years) as not being able to perform one of the essential job functions. Thus, the IDS team advises supervisors not to approve this medical leave. On the contrary, in regular cases, the IDS team guides supervisors to grant a medical leave; even if sometimes supervisors may want to deny a request, the IDS team suggests that they consider alternatives for accommodating the request.

Second, the IDS team advises supervisors to provide flexible schedule instead of granting a medical leave. The case study organization found that $83 \%$ of their medically supported requests were approved as written. By bringing in the IDS team that helps supervisors conduct interactive dialogues modifying requests and offering flexible scheduling, the organization reduces absence hours and improves operational efficiency by not always approving accommodation requests as written. Considering the example below: "...let's say that an employee has a job accommodation that was medically supported for 40 hours of time in a month to attend physical therapy. What we typically saw from the field is that [a supervisor] would just say okay, it's approved. Instead of just approving that across the board, [the IDS team] works with the supervisor... to move the employee's off day so that one of their days off is on a day that they can attend physical therapy... instead of just giving them 40 hours of medical leave, maybe we don't give them any leave and we just offer flexible scheduling... let's say there was once a week eight hours times 4. That's 32 hours right there, if we just move their off day... We're able to have the interactive dialogue with the employee, still accommodate them, but not have so much absenteeism..." (HR manager)

A couple of months after the IDS team was introduced, the preliminary result showed that it resulted in a $75 \%$ reduction in the number of absence hours and gave back about $\$ 75,000$ in efficiencies.

\subsection{Circuit of Systemic Integration}

The circuit of systemic integration emphasizes a fit between the accommodation practices facilitated by the WA system and the organization's business practices. The case study organization facilitates its approach to accommodating by creating an IDS team to support supervisors with accommodation decision making and protect business needs. In making a compromise between business needs and accommodation compliance, the WA system becomes legitimate.

Compared to the previous accommodation practices, the WA system fits better with the organization's business practices by bringing in the IDS team serving as an agent to assist supervisors with accommodation decision making. This introduction demonstrates that organizational changes are needed to make the system work for its intended purposes - better comply with law and provide services for disabled employees. These organizational changes include: (1) providing proactive resources to help supervisors easily understand and decide accommodations, (2) adjusting organizational structures by recruiting professionals that have relevant expertise to help balance business needs and accommodation compliance.

First, providing proactive resources for busy supervisors can help them more easily understand and operate the accommodation process. Prior to the introduction of the WA system, the case study organization provided multimedia accommodationrelated training materials to supervisors, including written training materials, a one-stop website that incorporated training videos, completed model interactive dialogue forms, etc., and an annual 
mandatory accommodation compliance training. Despite all these trainings offered to supervisors, they may still not understand the accommodation process and compliance well. The reason is that these retail store supervisors are often recent graduates and very busy with all aspects of a store operation and going through all kinds of trainings, among which the accommodation piece is a tiny piece. Thus, supervisors frequently overlook the accommodation trainings. These reactive resources did not help much in such an overloaded business setting.

To address this issue, the IDS team is designed to help before the need arises. Once a medically supported request is received, an IDS specialist will conduct a consultation meeting with a supervisor, help him/her review the employee's attendance analysis and an interactive dialogue process to talk with the employee, as well as provide additional training resources on how to conduct an interactive dialogue and explore an accommodation. An IDS specialist considered their role as a resource for supervisors in the excerpt below:

"[We] then really just make ourselves available as a resource to walk [supervisors] through any heartaches or sticking points that they have..."

With the help from these specialists, supervisors perceive the WA system as a "gift" for easier understanding and implementing the accommodation process, so they willingly accept the WA system and even complimented the system, such as "is it Christmas eve? Because I feel that we just got the best gift with this [WA system]." "I really like what I am seeing with the new [WA system]."

Second, adjusting organizational structures by introducing IDS specialists who are familiar with both the organization's business practices and accommodation process can help balance business needs and accommodation compliance. IDS specialists are hired from business units within the organization and are familiar with the accommodation process. They are able to advise supervisors on how to have an interactive dialogue with an employee who had a lot of absences in the last five years and did not perform essential job functions, instead of approving every leave request. In addition, they also help supervisors understand the flexibility of an interactive dialogue and the possibility to offer flexible scheduling rather than granting every request as written so that the organization's business needs are protected and employees are accommodated.

\section{Discussion}

\subsection{Design principles of IS using emancipatory pedagogy}

The literature review and empirical findings reveal the role of power relationships in the use of an accommodation management system. To make this system work, it needs to fit into the organization's business practices. Organizational changes (e.g., providing appropriate resources, adjusting organizational structures) are necessary as well.

Abstracting from the experience of IS design in the case study organization, we developed IS design principles using emancipatory pedagogy [10]. Emancipatory design principles, in line with the social inclusion context, improve communications between IS and stakeholders, promote a partnership where stakeholders can learn to resolve conflicts and achieve balance, value continuous learning and make necessary organizational changes, as well as build an emancipatory environment for all [10]. These principles support IS design to embrace complex power relationships and enable social inclusion.

Principle \#1: IS design should improve communications between IS and stakeholders by providing processes and resources to emphasize interactive dialogues. Since interactive dialogue is the foundation of compliance with the ADA and the EEOC's regulations [31], presenting evidence of whether or not participating in accommodation processes was in good faith, it is necessary to require supervisors to record their interactive dialogues with employees in an accommodation management system before they can make an accommodation decision. Moreover, after supervisors decide, having a "fail-safe" team examine the decision (modify or deny an accommodation) and interactive dialogues is beneficial for both employees and an organization itself. These approaches also help supervisors understand the importance of holding interactive dialogues. Additionally, providing training resources on interactive dialogues (e.g., specialists, videos) to supervisors can help increase the effectiveness of these dialogues. IS design should include these processes and resources to enable understandable communications between systems and users.

Principle \#2: IS design should promote a partnership where stakeholders can learn to resolve conflicts and achieve balance between accommodation compliance and business needs. Organizations are mandated to comply with the ADA and the EEOC's regulations, however, they would have not accepted an accommodation management system had it not fit with their business needs. Therefore, IS 
design in the accommodation process should consider balancing accommodation compliance and business needs. Since supervisors are often not familiar with accommodation compliance and relevant business impact, IS should be coupled with adequate resources to fit with supervisors' needs. For example, organizations could introduce specialists who are familiar with both their business practices and accommodation process to advise supervisors on accommodation issues because they can help provide insights into accommodation decision making that balances accommodation compliance and business needs. This design principle can be extended to other contexts embracing complex power relationships. IS should promote a partnership where stakeholders can learn to address any conflicts that may arise between different sides of the power relationships.

Principle \#3: IS design should value continuous learning and make necessary organizational changes to support IS to actually help comply with law and enable social inclusion. IS are sociotechnical systems. When an organization introduces a new technology but does not adjust social components that interact with the technology, the IS often does not work as it is designed [20][26]. Especially in the social inclusion context, multiple actors within that context may have different interests. The organizations must think more about how to make an IS fit into organizational practices while serving its intended purposes. Therefore, IS design should value continuous learning and make necessary organizational changes. In the accommodation context, organizations should make needed changes that suit their business practices in order to support an accommodation management system that will work effectively.

Principle \#4: IS design should build an emancipatory environment for all by proactively creating opportunities for disadvantaged groups. The extant literature and empirical data show that a major challenge in social inclusion practices is the awareness issue [12]. IS design should proactively create opportunities by raising awareness of social inclusion topics in order to build an emancipatory environment for all. In the accommodation context, supervisors often do not have sufficient knowledge of disability and accommodation, which will be unlikely to help create an emancipatory environment for disabled employees. Therefore, IS design should proactively create opportunities for disabled employees by providing multifaceted trainings on intranets and building feedback mechanisms (e.g., surveys) to educate and engage supervisors. These materials can focus on how to create an inclusive work environment and how to manage a fair and equitable accommodation process that emancipates disabled employees.

\subsection{Limitations and further research}

We also identify the limitations of this study and implications for further research. First, we focused on only one organization, which would cause concerns about the generalization of our findings. This is a common concern of single case studies. To address this issue, the generalization of our case study findings should be extrapolated to analytical generalizations [17] or to produce insights [33]. As we mentioned earlier, the case study organization and several other organizations that we interviewed have all used advanced accommodation management systems and have similar structures, roles, tasks, and processes. Therefore, using the case study organization's system to analyze the effect of power relationships on accommodation management systems likely has generalizable meanings. Further research will integrate other organizations we are studying into the analysis so that we can provide more comprehensive findings and in-depth understanding.

Second, due to confidentiality concerns, we were unable to conduct interviews with disabled employees from the same organization. As a key stakeholder in the accommodation process, disabled employees' role in the use of an accommodation management system and their power relationships with other stakeholders in that process would be important to study. Further research could explore how to use data of other stakeholders in one organization and data of disabled employees from different organizations to analyze power dynamics or other theoretical themes in a single study.

\section{Conclusion}

IS can be an effective tool to facilitate accommodation processes and promote social inclusion. This paper explored how an IS had been used in an organizational accommodation process. This paper employed the circuits of power framework to examine the role of power relationships in the use of IS. It also revealed that business considerations and organizational changes are needed to form legitimacy of the IS. Furthermore, this study provided a theoretical view of the design of IS using emancipatory pedagogy.

\section{References}

[1] Backhouse, J., Hsu, C. W., and Silva, L. 2006. "Circuits of Power in Creating De Jure Standards: Shaping an International Information Systems Security Standard," MIS Quarterly (30), pp. 413-438.

[2] Breen, J., Havaei, F., and Pitassi, C. 2019. "Employer Attitudes toward Hiring Persons with Disabilities in 
Armenia," Disability and Rehabilitation (41:18), pp. 2135-2142.

[3] Carter, M., and Grover, V. 2015. "Me, My self, and I(T): Conceptualizing Information Technology Identity and Its Implications," MIS Quarterly (39:4), pp. 931-957.

[4] Clegg, S. R. 1989. Frameworks of Power, London: Sage Publications.

[5] Coole, C., Radford, K., Grant, M., and Terry, J. 2013. "Returning to Work after Stroke: Perspectives of Employer Stakeholders, A Qualitative Study," Journal of Occupational Rehabilitation (23:3), pp. 406-418.

[6] Denny-Brown, N., O’Day, B., and McLeod, S. 2015. "Staying Employed: Services and Supports for Workers with Disabilities," Journal of Disability Policy Studies (26:2), pp. 124-131.

[7] Ekberg, K., Pransky, G. S., Besen, E., Fassier, J. B., Feuerstein, M., Munir, F., and Blanck, P. 2016. "New Business Structures Creating Organizational Opportunities and Challenges for Work Disability Prevention," Journal of Occupational Rehabilitation (26:4), pp. 480-489.

[8] Fragos, C., Karyda, M., and Kiountouzis, E. 2007. "Using the Lens of Circuits of Power in Information Systems Security Management," in TrustBus, C. Lambrinoudakis, G. Pemul, and A. M. Tjoa (eds.), Heidelberg: SpringerVerlag, pp. 228-236.

[9] Job Accommodation Network. 2014. "ADA Leave Beyond FMLA," ENews (12:3).

[10] Kane, G. C., Young, A. G., Majchrzak, A., and Ransbotham, S. 2021. "Avoiding an Oppressive Future of Machine Learning: A Design Theory for Emancipatory Assistants," MIS Quarterly (45:1), pp. 371-396.

[11] Katz, J. E., Rice, R. E., and Aspden, P. 2001. "The Internet 1995-2000: Access, Civil Involvement, and Social Interaction," American Behavioural Scientist (45:3), pp. 405-419.

[12] Kaye, H. S., Jans, L. H., and Jones, E. C. 2011. "Why Don't Employers Hire and Retain Workers with Disabilities?," Journal of Occupational Rehabilitation (21:4), pp. 526-536.

[13] Kennedy, H. 2020. "Recent Court ADA Case Review for Conflict Resolution Practitioners".

[14] Khayatzadeh-Mahani, A., Wittevrongel, K., Nicholas, D. B., and Zwicker, J. D. 2020. "Prioritizing Barriers and Solutions to Improve Employment for Persons with Developmental Disabilities," Disability and Rehabilitation (42:19), pp. 2696-2706.

[15] Klein, H. K., and Myers, M. D. 1999. "A Set of Principles for Conducting and Evaluating Interpretive Field Studies in Information Systems," MIS Quarterly (23:1), pp. 6794.

[16] Kuznetsova, Y., and Yalcin, B. 2017. "Inclusion of Persons with Disabilities in Mainstream Employment: Is It Really All about the Money? A Case Study of Four Large Companies in Norway and Sweden," Disability \& Society (32:2), pp. 233-253.

[17] Lee, A. S., and Baskerville, R. L. 2003. "Generalizing Generalizability in Information Systems Research," Information Systems Research (14:3), pp. 221-243.
[18] Lindsay, S., Cagliostro, E., Albarico, M., Mortaji, N., and Karon, L. 2018. "A Systematic Review of the Benefits of Hiring People with Disabilities," Journal of Occupational Rehabilitation (28:4), pp. 634-655.

[19] Mbiti, I., and Weil, D. 2011. "Mobile Banking: The Impact of M-Pesa in Kenya," Working Paper 17129, 1050 Massachusetts Avenue.

[20] Sarker, S., Chatterjee, S., Xiao, X., and Elbanna, A. 2019. "The Sociotechnical Axis of Cohesion for the IS Discipline: Its Historical Legacy and Its Continued Relevance," MIS Quarterly (43:3), pp. 695-720.

[21] Sarker, S., Xiao, X., Beaulieu, T., and Lee, A. S. 2018. "Learning from First-generation Qualitative Approaches in the IS Discipline: An Evolutionary View and Some Implications for Authors and Evaluators (PART 1/2)," Journal of the Association for Information Systems (19:8), pp. 752-774.

[22] Selwyn, N. 2004. "Reconsidering Political and Popular Understandings of the Digital Divide," New Media and Society (6:3), pp. 341-362.

[23] Silva, L. 2007. "Epistemological and Theoretical Challenges for Studying Power and Politics in Information Systems," Information Systems Journal (17:2), pp. 165-183.

[24] Silva, L., and Fulk, H. K. 2012. "From Disruptions to Struggles: Theorizing Power in ERP Implementation Projects," Information and Organization (22:4), pp. 227251.

[25] Smith, S., Winchester, D., Bunker, D., and Jamieson, R. 2010. "Circuits of Power: A Study of Mandated Compliance to an Information Systems Security 'De Jure' Standard in a Government Organization," MIS Quarterly (34:3), pp. 463-486.

[27] Strong, D. M., Volkoff, O., Johnson, S. A., Pelletier, L. R., Tulu, B., Bar-On, I., ... and Garber, L. 2014. "A Theory of Organization-EHR Affordance Actualization," Journal of the Association for Information Systems (15:2), pp. 53-85.

[28] The Americans with Disabilities Act. 1990. "The Americans with Disabilities Act Title I".

[29] Trauth, E. 2017. "A Research Agenda for Social Inclusion in Information Systems," Data Base for Advances in Information Systems (48:2), pp. 9-20.

[30] United Nations. 2015. "Transforming Our World: The 2030 Agenda for Sustainable Development," General Assembly.

[31] United States Equal Employment Opportunity Commission. 2011. "Questions and Answers on the Final Rule Implementing the ADA Amendments Act of 2008".

[32] United States Equal Employment Opportunity Commission. 2016. "Employer-Provided Leave and the Americans with Disabilities Act".

[33] United States Equal Employment Opportunity Commission. 2019. "Commissioner Charges and Directed Investigations".

[34] Walsham, G. 1995. "Interpretive Case Studies in IS Research: Nature and Method," European Journal of Information Systems (4:2), pp. 74-81. 